\title{
Pontus de Tyard, CEuvres complètes Tome IV, 2: Le Second Curieux, ou Second Discours de la nature du monde et de ses parties
}

\section{Dario Cecchetti}

\section{(2) OpenEdition \\ 1 Journals}

\section{Edizione digitale}

URL: http://journals.openedition.org/studifrancesi/2116

DOI: 10.4000/studifrancesi.2116

ISSN: 2421-5856

\section{Editore}

Rosenberg \& Sellier

\section{Edizione cartacea}

Data di pubblicazione: 1 aprile 2014

Paginazione: 133

ISSN: 0039-2944

\section{Notizia bibliografica digitale}

Dario Cecchetti, «Pontus de Tyard, Euvres complètes Tome IV, 2: Le Second Curieux, ou Second Discours de la nature du monde et de ses parties », Studi Francesi [Online], 172 (LVIII | I) | 2014, online dal 01 avril 2014, consultato il 18 septembre 2020. URL : http://journals.openedition.org/studifrancesi/ 2116 ; DOI : https://doi.org/10.4000/studifrancesi.2116

Questo documento è stato generato automaticamente il 18 settembre 2020.

\section{cc) (†) $\odot$}

Studi Francesi è distribuita con Licenza Creative Commons Attribuzione - Non commerciale - Non opere derivate 4.0 Internazionale. 


\title{
Pontus de Tyard, Euvres complètes Tome IV, 2: Le Second Curieux, ou Second Discours de la nature du monde et de ses parties
}

\author{
Dario Cecchetti
}

\section{NOTIZIA}

PONTUS DE TYARD, CEuvres complètes, sous la direction d'Eva KUSHNER, Tome IV, 2: Le Second Curieux, ou Second Discours de la nature du monde et de ses parties, édition de François ROUDAUT, Paris, Classiques Garnier, 2013 («Textes de la Renaissance», 184), pp. 408.

1 Nella meritoria impresa, avviata e diretta da Eva Kushner, dell'edizione critica delle CEuvres complètes di Pontus de Tyard esce ora un quinto volume. Dopo la pubblicazione, a opera di Jean Céard, del Premier Curieux (Paris, Classiques Garnier, 2010: vedi questi «Studi», 164, 2011, p. 396), François Roudaut, cui dovevamo già un importante lavoro su La Bibliothèque de P. de T. (Paris, Champion, 2008: vedi questi «Studi», 157, 2009, p. 158), ha ora curato egregiamente l'edizione del Second curieux, seconda parte di un trattato pubblicato come opera unitaria nel 1557 e poi ampliato e diviso in due discorsi o dialoghi - i due Curieux appunto - nel 1578. Nel 1587 Tyard pubblicherà insieme tutti i suoi Discours philosophiques, in numero di sei (Solitaire premier, Solitaire second, Mantice, Le Premier Curieux, Le Second Curieux, Scève ou Discours du Temps, de l'An et de ses parties). Si tratta di testi che passano attraverso revisioni: soprattutto il Second Curieux subisce un profondo rimaneggiamento, che pone all'editore problemi filologici. In questa edizione critica viene riprodotto il testo del 1587, collazionato con le varianti del 1557 e 1578 . Di particolare interesse sono le correzioni manoscritte autografe contenute nell'esemplare appartenuto a Tyard, correzioni che il moderno editore integra nella sua edizione. Ricchissima l'annotazione, che segue i seguenti principî: 1) precisare le fonti, 
cioè i testi che sono stati se non tradotti perlomeno ampiamente ricalcati; 2) stabilire una 'genealogia' di nozioni in modo da segnalare la posizione di Tyard in rapporto a una $o$ a più tradizioni (arricchendo le annotazioni con la citazione di passaggi anche lunghi, che permettono confronti accurati); 3) fare eventuali confronti con altri testi di Tyard in cui compaiono tematiche o espressioni affini. L'ampia introduzione (pp. 7-122) è un vero e proprio saggio monografico, che analizza la struttura dell'opera e il ruolo dei protagonisti, ma soprattutto ricostruisce il retroterra culturale dell'opera attraverso uno studio delle fonti: in particolare di quelle più significative, fra cui una posizione di rilievo occupa, con il suo trattato De harmonia mundi, l'umanista veneziano Francesco Zorzi, cui si aggiungono autori antichi e moderni come Sesto Empirico, Filone d'Alessandria, Agostino Steuco. Attraverso il confronto continuo con il testo di questi autori, soprattutto di Zorzi, viene ricostruito il discours di Tyard su alcune tematiche centrali del pensiero rinascimentale e particolarmente care al neoplatonismo lionese: l'origine delle anime, il microcosmo (in particolare nei suoi rapporti con il cielo), Dio, la natura di Dio presso popoli diversi, la creazione del mondo. 